\title{
A taxa de conclusão de curso da graduação nas universidades federais antes e depois do REUNI: as vicissitudes da implementação da política
}

\author{
Undergraduate courses completion rate in federal universities \\ before and after REUNI: the vicissitudes of the policy implementation
}

\author{
Mara Águida Porfírio Moura ${ }^{1}$ \\ ${ }^{1}$ Universidade Federal do Piauí | Departamento de Ciências da Administração e Informática \\ Parnaíba | PI | Brasil. Contato: maraaguida@ hotmail.com \\ http://orcid.org/0000-0002-1608-2683
}

Guiomar de Oliveira Passos ${ }^{2}$

${ }^{2}$ Universidade Federal do Piauí | Programa de Pós-Graduação em Políticas Públicas

Teresina | PI | Brasil. Contato: guiomar@ufpi.edu.br

http://orcid.org/0000-0002-6106-4900

Resumo: Examina-se o alcance da meta do Reuni de elevar a taxa de conclusão dos cursos de graduação presenciais para $90 \%$, verificando os resultados alcançados nas regiões por meio dos parâmetros definidos pelos formuladores. Analisam-se os resultados da implementação, comparando os fins estipulados com os atingidos com base nos documentos e regulamentos do Programa, relatórios de acompanhamento e dos Censos de Educação Superior de 2008 a 2012. Constatou-se que antes do Reuni a TCG em 57,2\% das IFEs era de 67 a $90 \%$ e no final, em 58,5\%, de 44 a 67\%, havendo mais unidades próximas dessa do que daquela. $\mathrm{O}$ indicador foi menor em todas as regiões, sendo maior a redução na Norte, que teve TCG menor $17,3 \%$ no final e registrou 5 TCG igual ou superior a $90 \%$ durante a implementação enquanto na Sudeste foram 13. Nesta, teve-se o melhor resultado em 2012 - TCG de 108,5\%, na Universidade Federal de Alfenas, naquela, o pior, 36\% da Universidade Federal Rural da Amazônia - UFRA, cujas TCGs no início eram, respectivamente, $102,5 \%$ e $64,7 \%$. Portanto, uma já apresentava os resultados desejados, a outra distava $25,3 \mathrm{pp}$. As diferenças, contudo, não foram consideradas pelos formuladores da política quando traçaram a meta, evidenciando as limitações do seu diagnóstico ou do seu modelo causal e, fundamentalmente, como o contexto da prática altera as políticas formuladas. Por conseguintes, o reduzido número de instituições que alcançaram a meta indica tanto problemas na formulação do texto do Reuni quanto a recriação a que esse foi submetido pelo contexto.

Palavras-chave: Programa REUNI. Implementação de Políticas Públicas. Taxa de Conclusão de Curso de Graduação.

Abstract: The reaching of the REUNI goal to raise classroom-based undergraduate courses completion rate to $90 \%$ is examined by verifying the results achieved in the regions through the parameters set by the formulators. The results of the implementation are analyzed by comparing stipulated ends with the ones that were reached on the basis of the Program documents and regulations, follow-up reports and the Higher Education Censuses from 2008 to 2012. It could be seen that before REUNI, the UCCR in 57.2\% of the Teaching Federal Institutions was 67 to $90 \%$ and that at the end in 58.5\%, from 44 to $67 \%$, with more units coming closer to the latter. The indicator was lower in all regions, with a reduction in the North, which had a lower UCCR of $17.3 \%$ at the end, and registered 5 UCCR equal to or higher than $90 \%$ during the implementation, while in the Southeast there were 13. The best result was reached by this one in $2012-108.5 \%$ UCCR, at the Federal University of Alfenas, the worst was reached by the other one, $36 \%$ at the Federal Rural University of Amazonia - UFRA whose UCCRs were 102.5\% and $64.7 \%$, respectively. Therefore, one already presented the desired results, the other one was far by 25.3 pp. Differences, however, were not considered by the policymakers when they set the goal, highlighting the limitations of their diagnosis or causal model and, fundamentally, how the practice context alters the formulated policies. As a result, the small number of institutions that have reached the goal indicates both problems in the formulation of the REUNI text and the re-creation to which it has been subjected by the context.

Key words: REUNI Program. Public Policies Implementation. Undergratuate Course Completion Rate.

DOI: http://dx.doi.org/10.1590/S1414-40772019000200010 
Este é um artigo publicado em acesso aberto (Open Access) sob a licença Creative Commons Attribution Non-Commercial, que permite uso, distribuição e reprodução em qualquer meio, sem restrições desde que sem fins comerciais e que o trabalho original seja corretamente citado. https://creativecommons.org/licenses/by-nc/4.0/

$$
\text { Recebido em: } 2 \text { de julho de } 2018 \quad \text { Aprovado em: } 9 \text { de junho de } 2019
$$

\section{Introdução}

Este estudo, parte da tese de doutorado apresentada no Programa de Políticas Públicas da Universidade Federal do Piauí, examina o alcance da meta do Reuni de elevar a "taxa de conclusão dos cursos de graduação presenciais para noventa por cento" até 2012 que era uma das condições previstas pelo Decreto $\mathrm{n}^{\circ}$ 6.096, de 24 de abril de 2007, para ampliar o acesso à educação superior (BRASIL, 2007a).

Para isso, comparam-se os fins estipulados com os alcançados, verificando os resultados em todas as regiões por meio dos parâmetros de aferição definidos pelos formuladores da política, uma vez que não seria adequado avaliá-la com regra distinta da estabelecida na formulação. Desse modo, examina como a política, na expressão de Bowe, Ball e Gold (1992 apud MAINARDES, 2006, p. 52), do "contexto da produção do texto", se efetiva no "contexto da prática" ou, como diz Frey (2000, p. 228), “[...] até que ponto a encomenda da ação foi cumprida [...]" (FREY, 2000, p. 228).

Por conseguinte, acrescenta-se, aos estudos do Programa, a análise dos resultados de sua implementação, entendendo-a como uma etapa do 'ciclo de política' em que são executadas as atividades que permitem que ações definidas quando da formulação da política sejam efetivadas. Essa é, segundo Silva e Melo (2000, p. 4), a visão clássica da implementação, em que não apenas se privilegia a formulação como esta tem por base um diagnóstico assentado em todas as informações e o formulador dispõe de um modelo causal apropriado.

De qualquer modo, é um momento crucial, em que se planeja e organiza o aparelho administrativo e "os recursos humanos, financeiros, materiais e tecnológicos para executar a política” (SARAIVA, 2006 apud RUA; ROMANINI, 2012, p. 7), sendo, por conseguinte, uma etapa da política do qual muito depende seu sucesso ou fracasso. Suas vicissitudes, dizem Silva e Melo (2000, p. 3), "têm sido entendidas como uma das dimensões cruciais se não a variável central - para explicação dos insucessos dos governos em atingir os objetivos estabelecidos no desenho das políticas públicas" (SILVA; MELO, 2000, p. 3).

O que aqui se examina é se a meta traçada na formulação foi alcançada ou se a política delineada nos textos legais do Reuni foi reinterpretada ou mesmo recriada no "contexto da prática", como dizem Bowe, Ball e Gold (1992 apud MAINARDES, 2006, p. 53). Para isso, ao 
lado da pesquisa bibliográfica em suportes impressos e/ou eletrônicos sobre o Reuni e a implementação das políticas públicas, a pesquisa documental está consubstanciada na legislação que instituiu o Programa, nas normas e textos regulamentadores, relatórios de acompanhamento e dados do Censo de Educação Superior publicados pelo INEP (2008, 2009, 2010, 2011, 2012).

Estrutura-se o artigo em cinco partes, sendo a primeira esta introdução. A segunda contextualiza o Reuni na política educacional, estabelecendo os nexos com as demandas das Instituições Federais de Ensino Superior e com os planos governamentais, notadamente com o Plano de Desenvolvimento da Educação (PDE). A terceira delineia-se o processo de implementação em termos do planejamento, organização e definição dos parâmetros de acompanhamento. A quarta analisa as taxas de conclusão dos cursos de graduação alcançadas pelas IEFs, utilizando-se medidas de tendência central e de dispersão, avaliando os resultados nas regiões brasileiras e identificando as instituições que para isso contribuíram. A última analisa os resultados, isto é, o alcance da meta traçada na formulação

\section{Programa Reuni na Política Educacional}

O Programa REUNI originou-se da Proposta de Expansão e Modernização do Sistema Público Federal de Ensino Superior elaborada e divulgada pelos representantes da Associação Nacional de Dirigentes das IFEs - ANDIFES, em 05 de agosto de 2003, (ANDIFES, 2003), nas discussões do projeto da 'Universidade Nova' em 2006, apresentado pelo Prof. Naomar Monteiro, na época, reitor da Universidade Federal da Bahia - UFBA (LIMA; AZEVEDO; CATANNI, 2008; TONEGUTTI; MARTINS, 2009; SABÓIA, 2015), e se concretizou com o Plano de Desenvolvimento da Educação - PDE 2007, regulamentado pelo Decreto $\mathrm{n}^{\circ}$ $6.094 / 2007$.

O PDE, ao tempo em que apresenta uma concepção sistêmica de educação que não apenas articula todos os níveis e modalidades de ensino como a vincula ao território e ao desenvolvimento, consiste "num conjunto de programas que visam dar consequências às metas quantitativas estabelecidas" no Plano Nacional de Educação - PNE (2001-2010) (BRASIL, 2007a, p. 7). Os programas educacionais previstos pelo PDE - 2007, mais de quarenta, organizam-se "em quatro eixos norteadores: educação básica, educação superior, educação profissional e alfabetização" (BRASIL, 2007a). O REUNI, ao lado do Plano Nacional de Assistência Estudantil (PNAES), do Financiamento ao Estudante do Ensino Superior (FIES), e do Programa Universidade para Todos (PROUNI), integram o eixo do ensino superior. 
Para isso, "os meios a serem empregados", conforme o PDE (BRASIL, 2007a, p. 28), são: “a expansão dos cursos noturnos, a ampliação da mobilidade estudantil, a revisão da estrutura acadêmica e a diversificação das modalidades de graduação". Desse modo, o PDE (2007), ia ao encontro dos anseios de expansão da Associação Nacional de Dirigentes das IFEs - ANDIFES, e das ideias dos que defendiam uma "Universidade Nova".

A ideia da "Universidade Nova", defendida pelo reitor da Universidade Federal da Bahia, professor Naomar Monteiro, previa uma profunda reformulação no modelo acadêmico do ensino superior público que passaria a ter três ciclos: o $1^{\circ}$ ciclo do bacharelado interdisciplinar, o $2^{\circ}$ ciclo de formação profissional e o $3^{\circ}$ ciclo da pós-graduação (LIMA; AZEVEDO; CATANNI, 2008; TONEGUTTI; MARTINS, 2009). Para, Naomar Monteiro, era preciso uma "transformação radical da atual arquitetura acadêmica da universidade pública brasileira" (TONEGUTTI; MARTINS, 2009, p. 2), sem a qual não seria possível superar os desafios colocados pela sociedade brasileira naquele momento. Essa ideia encontra meios de se materializar, dizem Lima, Azevedo e Catanni (2008) com o Reuni, pois possibilitava, como queria o PDE (2007), superar "itinerários rígidos, desperdícios de créditos, imobilidade e especialização precoce", característicos das instituições de ensino superior brasileiros, que eram, na avaliação do Plano de Desenvolvimento, "incompatíveis com uma estrutura universitária à altura dos novos desafios da ciência” (BRASIL, 2007b, p. 28).

O redesenho curricular, conforme previsto no PDE (2007), e confirmado nas Diretrizes Gerais do REUNI se daria: "valorizando a flexibilização e a interdisciplinaridade, diversificando as modalidades de graduação e articulando-a com a pós-graduação, além do estabelecimento da necessária e inadiável interface da educação superior com a educação básica[...]" (BRASIL, 2007c, p. 5). Já a ampliação do acesso ocorreria pelo "melhor aproveitamento da estrutura física e do aumento do qualificado contingente de recursos humanos existente nas universidades federais [...]" (BRASIL, 2007a, p. 5). Desse modo, vinculava a expansão do ensino superior à eficiência e à eficácia no uso dos recursos financeiros, materiais e humanos.

Esses termos, eficiência e eficácia, constituem ideia central no objetivo do REUNI, que é "criar condições para a ampliação do acesso e permanência na educação superior, no nível de graduação, pelo melhor aproveitamento da estrutura física e de recursos humanos existentes nas universidades federais"; e na meta: "elevação gradual da taxa de conclusão média dos cursos de graduação presenciais para noventa por cento e da relação de alunos de graduação em cursos presenciais por professor para dezoito, ao final de cinco anos, a contar do início de cada plano" (BRASIL, 2007a). A eficiência e a eficácia, por conseguinte, viabilizariam a expansão nas IFEs. 
Desse modo, "inverte-se a lógica que presidia as relações entre as universidades federais e o MEC", substituindo a lógica do controle dos processos, típicos do modelo burocrático até então dominante pela da pactuação e dos resultados previamente pactuados [...]" (ARAÚJO; PINHEIRO, 2010, p. 660). A pactuação, por meio de um contrato de gestão entre as instituições federais de ensino superior e o MEC, materializavam-se por meio dos planos de reestruturação e expansão das instituições. Cada plano apresentava um diagnóstico da situação da instituição, as metas a serem alcançadas, um cronograma de execução das estratégias e etapas a serem implementadas para atingir o objetivo e a meta propostos no Programa (BRASIL, 2007a).

Os recursos para execução e implementação dos Planos, conforme o art. $3^{\circ}$ do Decreto instituidor, ficariam reservados para cada universidade federal, "na medida da elaboração e apresentação dos respectivos planos de reestruturação, a fim de suportar as despesas decorrentes das iniciativas propostas" (BRASIL, 2007a), ressaltando que, como estabelece o mesmo artigo no $\S 3^{\circ}$, o "atendimento dos planos é condicionado à capacidade orçamentária e operacional do Ministério da Educação". Os planos, conforme art. $4^{\circ}$ do referido Decreto, respeitando a vocação e os princípios de autonomia das universidades, deveriam indicar a estratégia e as etapas para a realização dos objetivos referidos no art. 1응 (BRASIL, 2007a). Desse modo, não preconizava o Decreto um modelo único, pelo contrário, respeitava a heterogeneidade organizacional das instituições. Consequentemente, observam Araújo e Pinheiro (2010, p. 662), o Ministério "criava condições mais efetivas de cobrança dos resultados", pois, conforme explicam, "é a própria instituição que define as metas a serem alcançadas" tomando deliberações no escopo de sua autonomia.

Essa autonomia de escolha na formulação das estratégias para o alcance dos objetivos e metas propostos pelas instituições, após aprovados pelo Ministério da Educação, conforme o art. $6^{\circ}$, daria "origem a instrumentos próprios, que fixarão os recursos financeiros adicionais destinados à universidade, vinculando os repasses ao cumprimento das etapas", condicionando, assim, o financiamento ao cumprimento de metas previamente acordadas nos Contratos de Gestão (BRASIL, 2007a; 2007b). Este, como observam Lima, Azevedo e Catanni (2008, p. 24), assemelhando-se, assim como a definição de metas e a vinculação do alcance dos objetivos à eficiência e à eficácia, às "propostas do MARE (Ministério da Administração Federal e da Reforma do Estado), da época do Ministro Bresser Pereira”.

De qualquer modo, o que preconizavam os documentos do Reuni, era que o processo de implementação do REUNI devia estar alinhado à cultura organizacional da instituição, por meio de estratégias com foco no objetivo e meta propostos. 


\section{Implementação do REUNI: planejamento, organização e parâmetros de acompanhamento}

A implementação tinha início com a elaboração dos planos de reestruturação e expansão, conforme orientações do Grupo Assessor nomeado pela Portaria $n^{\circ} 552 \mathrm{SESu} / \mathrm{MEC}$, de 25 de junho de 2007 e determinações do Decreto $n^{\circ}$ 6.096/2007. Esses deveriam ser aprovados pelo Órgão Superior da instituição proponente e, em seguida, enviados para o Ministério da Educação via Sistema Integrado de Planejamento, Orçamento e Finanças SIMEC, a fim de serem avaliados em termos da consistência e exequibilidade de suas proposições e as exigências do Decreto (BRASIL, 2007a, p. 6).

Após aprovação, a proposta, conforme o art. $6^{\circ}$ do Decreto, dava origem "ao termo de pactuação de metas e de fixação de recursos humanos e financeiros adicionais destinados à universidade" (BRASIL, 2007a). Os repasses, ainda conforme o art. 6 , “condicionados aos cumprimentos das etapas previstas no projeto" (BRASIL, 2007a), tinham início, no primeiro semestre de 2008, para aqueles que apresentassem suas propostas até 29 de outubro de 2007 e, no segundo semestre, para as apresentadas até 17 de dezembro de 2007, conforme estabelecido no cronograma proposto nas Diretrizes Gerais do REUNI, em agosto de 2007.

No primeiro prazo, 42 IFES aderiram ao Programa e, no segundo, mais 11, o que mostra, por um lado, o interesse das instituições e, por outro, que todas, já em 2008, podiam dispor dos recursos necessários à implementação e, por conseguinte, podiam ser acompanhadas por meio da Plataforma PingIFES, que reuniria todos os dados relativos ao cumprimento das metas produzidos pelo INEP, CAPES e Sistema Nacional de Avaliação da Educação Superior (SINAES), bem como por visitas in loco em relação à modernização das estruturas curriculares, ao "desempenho docente e discente, à evolução das avaliações da CAPES, à evolução da produção científica do quadro docente e à participação do quadro docente da pós-graduação em atividades da graduação" (BRASIL, 2007c, p. 20).

A avaliação do cumprimento da meta tinha por base, como previsto no $\S 1^{\circ}$ do art. $1^{\circ}$ do Decreto $\mathrm{n}^{\circ}$ 6.096/2007, os parâmetros definidos pelo Ministério da Educação por meio da Portaria $\mathrm{n}^{\mathrm{o}} 552$ SESu/MEC, de 25 de junho de 2007, e consistiam em dois indicadores:

a) Taxa de conclusão dos cursos de graduação (TCG) -relação entre o total de diplomados nos cursos de graduação presenciais (DIP) num determinado ano e o total de vagas de ingressos oferecidas pela instituição (ING 5 ) cinco anos antes (BRASIL, 2007c, p. 14).

b) Relação de alunos de graduação Presencial por Professor (RAP) -relação entre a matrícula projetada em cursos de graduação presenciais (estimativa da capacidade de atendimento da universidade em função do número de vagas oferecidas anualmente em 
seus processos seletivos e a duração dos cursos) e a medida ajustada do corpo docente ${ }^{1}$ (BRASIL, 2007c. p. 17).

Esses parâmetros, tendo em vista "garantia de qualidade acadêmica" (BRASIL, 2007c, p. 10), eram complementados com a avaliação do cumprimento das diretrizes previstas no art. $2^{\circ}$ do Decreto 6.096/2007 estruturadas em seis dimensões: Ampliação da oferta de educação superior pública; "Reestruturação acadêmica - curricular; Renovação pedagógica da educação superior; Mobilidade intra e interinstitucional; Compromisso social da instituição e o Suporte da pós-graduação ao desenvolvimento e aperfeiçoamento qualitativo dos cursos de graduação" (BRASIL, 2007c, p. 11-12).

Desse modo, contemplava-se, a expansão do acesso e do número de vagas, expressa no objetivo e metas quantitativas, e a reestruturação das IFES, consignada nas metas qualitativas prevista em cada uma das dimensões do Programa (BRASIL, 2007c).

Expõe-se, a seguir, as taxas de conclusão de curso alcançadas pelas IFEs.

\section{Taxa de Conclusão dos Cursos de Graduação -TCG nas IFEs e a Meta do REUNI}

A aferição da Meta Global, com base nos indicadores estabelecidos pela Portaria n 552 SESu/MEC 2007, em relação ao REUNI, tem como corpus as 53 instituições que aderiram ao Programa de forma voluntária, conforme o Primeiro Relatório do REUNI (2008). Para tanto, as instituições são organizadas por regiões, conforme a Tabela 1.

Tabela 1 - Instituições e número de Relatórios de Gestão avaliados entre 2008 e 2012.

\begin{tabular}{|c|c|c|}
\hline Regiões & IFEs & $\mathbf{N}^{0}$ de IFEs \\
\hline NORTE & UNIFAP, UFAC, UFAM, UFPA, UFT, UNIR, UFRR, UFRA. & 8 \\
\hline NORDESTE & $\begin{array}{l}\text { UFAL, UFBA, UFC, UFMA, UFPB, UFPE, UFPI, UFS, } \\
\text { UFRN, UFERSA, UFRB, UFCG, UFRPE, UNIVASF. }\end{array}$ & 14 \\
\hline SUL & $\begin{array}{l}\text { UFPR, UFPel, UFSC, FURG, UTFPR, UFCSPA, UFSM, } \\
\text { UFRGS. }\end{array}$ & 8 \\
\hline SUDESTE & $\begin{array}{l}\text { UFES, UFMG, UFV, UFJF, UFLA, UFSJ, UFOP, UFU, } \\
\text { UFVJM, UNIFAL, UNIFEI, UFRJ, UFRRJ, UNIFESP, } \\
\text { UFSCar, UFTM, UFF, UNIRIO. }\end{array}$ & 18 \\
\hline CENTRO-OESTE & UNB, UFG, UFMT, UFMS, UFGD. & 5 \\
\hline TOTAL & & 53 \\
\hline
\end{tabular}

Fonte: Elaborado pela autora com base nos relatórios de Gestão das IFES de 2008 a 2012. 
Os resultados da TCG, alcançados pelas 53 instituições, expostos na Tabela 2, mostram que as instituições em 2008 se concentravam entre 67 a 90\%, com 57,2\% das IFEs, em 2009, já se verifica redução nessa faixa para 49,1\% e, a partir de então, a maioria vai apresentar taxa de 44 a 67\%, sendo 45,3\% delas em 2010, 49,1\% em 2011 e 58,5\% em 2012.

Tabela 2 - Distribuição das IFEs segundo a frequência da TCG registrada entre 2008 e 2012

\begin{tabular}{|c|c|c|c|c|c|c|c|c|c|c|}
\hline \multirow[t]{2}{*}{$\mathrm{TCG}$} & \multicolumn{2}{|c|}{2008} & \multicolumn{2}{|c|}{2009} & \multicolumn{2}{|c|}{2010} & \multicolumn{2}{|c|}{2011} & \multicolumn{2}{|c|}{2012} \\
\hline & abs. & $\%$ & abs. & $\%$ & abs. & $\%$ & abs. & $\%$ & abs. & $\%$ \\
\hline Menor de 21 & 1 & 2 & & & 1 & 1,9 & & & & \\
\hline $21-44$ & 2 & 4 & 2 & 3,8 & 4 & 7,6 & 2 & 3,8 & 8 & 15 \\
\hline $44-67$ & 12 & 24,5 & 19 & 35,9 & 24 & 45,3 & 26 & 49,1 & 31 & 58,5 \\
\hline $67-90$ & 28 & 57,2 & 26 & 49,1 & 17 & 32,1 & 22 & 41,5 & 13 & 24,6 \\
\hline A partir de 90 & 6 & 12,3 & 6 & 11,2 & 7 & 13,1 & 3 & 5,6 & 1 & 1,9 \\
\hline TOTAL & $49 *$ & 100 & 53 & 100 & 53 & 100 & 53 & 100 & 53 & 100 \\
\hline
\end{tabular}

Fonte: Elaborado pela autora a partir dos dados das IFEs contidos na Sinopse da Educação Superior de 2004 a 2012.

*As Instituições: UFGD, UFRB, UFERSA e UFCSPA não apresentaram os dados no ano de 2008.

Então, há uma contínua redução da taxa nas instituições, verificando-se progressivo aumento no percentual de instituições nas faixas com menores TCG, (de 4\% a 15\%, na de 21 44; de 24,5\%, para 58,5\%, na de 44-67) e, consequentemente, redução no percentual de instituições nas faixas superiores a 67\% (de 57, 2\% para 24,6\%, na de 67-90; de 12,3\% para 1,9\% de mais de 90\%). De fato, quando se compara a frequência da TCG, em 2008, com a de 2012, constata-se que, em 2008, 69,5\% das instituições encontravam-se com a TCG, entre 67 a mais de $90 \%$, já em 2012, apenas 26,5\% alcançaram esse resultado.

A análise estatística, tendo por base medidas de tendência central (média) e de dispersão (desvio padrão e coeficiente de variação), exposto na Tabela 4, mostram declínio em todas as medidas, salvo em 2010 em que o desvio padrão e o coeficiente de variação aumentaram, indicando a redução da heterogeneidade entre as instituições, isto é, que a medida que a média foi reduzindo mais instituições ficaram em torno dela.

Tabela 4 - Média, Desvio Padrão e Coeficiente de Variação da TCG das IFEs, de 2008 a 2012

\begin{tabular}{cccc}
\hline Ano & Média & Desvio Padrão & Coeficiente de Variação \\
\hline 2008 & 63,8 & 24,3 & 38,2 \\
2009 & 67,6 & 25,5 & 37,7 \\
2010 & 65,8 & 32,0 & 48,6 \\
2011 & 62,2 & 20,5 & 33,0 \\
2012 & 55,9 & 21,2 & 37,9 \\
\hline
\end{tabular}

Fonte: Elaborado pela autora a partir dos dados das IFEs contidos na Sinopse da Educação Superior de 2004 a 2012. 
A média nacional, no início do REUNI, em 2008, era de 63,8\%, valor que já era $29,11 \%$ menor que os $90 \%$ proposto no Programa. Ao final, em 2012, foi de 55,9\%, evidenciando, a redução desse indicador após a implementação do Programa nas IFEs e uma diferença de 34,1\% em relação a meta. A maior média, 67,6\%, foi registrada em 2009. A partir daí, reduz a cada ano, passando para 65,8\% em 2010; 62,2\% em 2011; e 55,9\% em 2012, indicando que não apenas a meta traçada não era alcançada como a implementação do REUNI impactava negativamente no desempenho das IFEs.

O desvio padrão das IFEs, variou de 24,3 a 21,2 entre 2008 e 2012, apontando que os resultados eram mais distantes da média no início do Programa do que no seu finalisto é, que a situação era mais heterogênea antes do que depois. O coeficiente de variação, medida relativa de dispersão útil para a comparação em termos relativos do grau de concentração em torno da média de séries distintas (ROCHA, 2014), ficou entre 38,2\% e 37,9\%, demonstrando que, os resultados das instituições eram diversos, isto é, heterogêneos, tendo alcançado em 2010 a maior variação.

A análise por região exposta na Tabela 5 mostra que nenhuma região conseguiu alcançar a Taxa de Conclusão de Curso de Graduação - TCG estabelecida no Decreto n ${ }^{\circ}$ 6.096/2007, sendo o pior resultado o da região norte com $48,3 \%$, e o melhor na região sudeste com $68,3 \%$.

Tabela 5 - Média da Taxa de Conclusão de Curso de Graduação das Regiões no início (2008) e no final do Reuni (2012)

\begin{tabular}{cccccc}
\hline REGIÃO & $\mathbf{2 0 0 8}$ & $\mathbf{2 0 0 9}$ & $\mathbf{2 0 1 0}$ & $\mathbf{2 0 1 1}$ & $\mathbf{2 0 1 2}$ \\
\hline NORTE & 58,4 & 71,9 & 61,6 & 82,6 & 48,3 \\
\hline NORDESTE & 63,8 & 77,9 & 54,5 & 61,7 & 55,5 \\
\hline SUL & 69,0 & 66,0 & 73,9 & 66,9 & 62,9 \\
\hline SUDESTE & 79,8 & 80,8 & 87,0 & 70,7 & 68,3 \\
\hline CENTRO-OESTE & 67,4 & 63,9 & 58,6 & 65,4 & 59,7 \\
\hline MÉDIA GERAL & $\mathbf{6 7 , 6}$ & & & $\mathbf{5 8 , 9 4}$ \\
\hline
\end{tabular}

Fonte: Elaborado pela autora a partir dos dados das IFEs contidos na Sinopse da Educação Superior de 2004 a 2012

A comparação da média geral das regiões evidencia o declínio, pois de 67,6\% em 2008 passou para 58,9\% em 2012, sendo superada nas regiões sul $(62,9 \%)$, sudeste $(68,3 \%)$ e centrooeste $(59,7)$, sugerindo que os efeitos da expansão do Reuni no desempenho foram maiores nas regiões norte $(48,3 \%)$ e nordeste $(55,5 \%)$. Contudo, como demonstrado na Tabela 6 , a variação entre 2008 e 2012 foi de 17,3\%, na região norte, 14,41\% na Sudeste, 13,1\% na Nordeste, $11,42 \%$ na Centro-Oeste e $8,84 \%$ na região sul. 
Tabela 6 - Declínio da Média da Taxa de Conclusão do Curso de Graduação das IFEs do REUNI, de 2008 a 2012

\begin{tabular}{cccc}
\hline \multirow{2}{*}{ REGIÃO } & TAXA DE CONCLUSÃO DO CURSO - TCG & \multirow{2}{*}{ DECLÍNIO \% } \\
\cline { 2 - 4 } & $\mathbf{2 0 0 8}$ & $\mathbf{2 0 1 2}$ & 17,3 \\
\hline NORTE & 58,4 & 48,3 & 13,1 \\
\hline NORDESTE & 63,8 & 55,5 & 8,84 \\
\hline SUL & 69,0 & 62,9 & 14,41 \\
\hline SUDESTE & 79,8 & 68,3 & 11,42 \\
\hline CENTRO-OESTE & 67,4 & 59,7 & \\
\hline
\end{tabular}

Fonte: Elaborado pela autora a partir dos dados das IFEs contidos na Sinopse da Educação Superior de 2004 a 2012

A região sudeste mesmo com um declínio de $14,41 \%$, maior inclusive que o registrado na região nordeste, manteve-se, ainda que distante 21,7 pontos percentuais da TCG de $90 \%$ estabelecida no Decreto, com a melhor taxa média regional (68,3\%). Essa é fruto dos resultados de suas instituições - 8 das 10 com as maiores taxas; 13 ocorrências da TCG igual ou superior a $90 \%$ ao longo do período de implementação do Reuni, enquanto nas regiões Norte e Nordeste foram 5 ocorrências e no Sul 1, e 61\% apresentarem TCG superior à 87,5\% das localizadas na região Norte, à $64 \%$ das da região Nordeste, à $60 \%$ da região Centro-Oeste e à $50 \%$ das da região Sul.

As diferenças regionais se explicitam na comparação das melhores taxas de cada uma ao final do Programa em 2012: enquanto na região Sudeste, a melhor foi de 108,5\%, na Universidade Federal de Alfenas - UNIFAL, e na região Sul de 84,4\% na Universidade Federal de Ciências da Saúde de Porto Alegre - UFCSPA, a melhor na região Norte foi de 63,7\%, na Universidade Federal do Pará - UFPA. Até mesmo as piores taxas do Sul, de 42,9\% na Universidade Tecnológico Federal do Paraná - UTFPR, e do Sudeste, 45,1\%, da Universidade Federal Rural do Rio de Janeiro - UFRRJ, são maiores do que a do Norte, 36\% da Universidade Federal Rural da Amazônia - UFRA.

A meta traçada não contemplava as diferenças sociais e econômicas das regiões, assim como a história institucional, os tipos de cursos ou mesmo a situação anterior em relação aos indicadores utilizados para mensurá-la. A TCG da Universidade Federal de Alfenas - UNIFAL, por exemplo, melhor resultado em 2012, em 2007, antes da implementação do Reuni, era 102,3\% enquanto a da Universidade Federal Rural da Amazônia - UFRA, o pior resultado, era de $64,7 \%$.

A meta parece ter sido traçada sem as informações necessárias para sua elaboração, ou, pelo menos, sem uma avaliação da situação das instituições frente aos indicadores 
estabelecidos. O não alcance da meta pela grande maioria das instituições, portanto, longe de evidenciar 'desvios de rota', isto é, problemas da implementação, revelam problemas da formulação em que os elaboradores, diferentemente do que diz a visão clássica da implementação, não dispõem de diagnóstico correto e das informações necessárias ao desenho das proposições ou o modelo causal sobre o qual assenta suas proposições não é válido.

\section{Conclusão}

Este estudo, valendo-se dos parâmetros de aferição definidos pelos formuladores do Reuni, examinou se a meta traçada de elevar a "taxa de conclusão dos cursos de graduação presenciais para noventa por cento" até 2012 foi alcançada. Desse modo, analisa os resultados da implementação, entendida como a fase da política pública em que são efetivadas as ações definidas na formulação da política, comparando os fins estipulados com os alcançados.

A taxa de conclusão de cursos de graduação desejada viabilizaria, ao lado elevação do número de alunos por professor, a expansão da oferta de vagas no ensino superior objetivada pelo Plano de Desenvolvimento da Educação de onde se originava, sendo a um só tempo expressão de modelo de universidade flexível, maleável, interdisciplinar e de eficiência e eficácia. Sua definição assentava-se num pacto entre as instituições de ensino superior e o Ministério da Educação, cabendo a este o aporte financeiro para a viabilizar as ações e a aquelas executar seus planos de reestruturação e expansão, elaborados a partir de suas condições e cultura organizacional, e a avaliação dos resultados aferidos por meio de indicadores definidos pelos formuladores.

Cinquenta e três instituições aderiram ao Programa e os resultados, aferidos por meio dos parâmetros definidos pelos formuladores da política ao fim dos cinco anos de implementação (2008 a 2012), mostram que a TCG que era de 67 a 90 em 57\% das IFEs passou para 44 a 67 em 58,5\%. Por conseguinte, enquanto antes, mais da metade tinha a TCG superior a 67\%, após a implementação, mais da metade tinha menos de 67\%, existindo apenas uma instituição que, em 2012, tinha a taxa desejada pelo Programa de 90\%, a Universidade Federal de Alfenas - UNIFAL, localizada na cidade de Alfenas em Minas Gerais.

A verdade é que a situação, como evidenciado pelo desvio padrão de 24,3 em 2008 e de 21,2 em 2012 e pelo coeficiente de variação nesses anos de 38,2\% e 37,9\%, é diversa entre as beneficiárias, sendo maior a heterogeneidade no início do que no final quando a média reduziu, o que atesta que mais instituições diminuíram sua TCG. Isso ocorreu em todas as regiões, sendo, contudo, maior na Norte 17,3\% em que foram registradas apenas 5 ocorrências da TCG igual 
ou superior a $90 \%$ ao longo do período de implementação do Reuni enquanto na região sudeste foram 13. Nesta, teve-se melhor resultado ao final do Programa - TCG de 108,5\%, na Universidade Federal de Alfenas, naquela, o pior, 36\% da Universidade Federal Rural da Amazônia - UFRA.

As diferenças mostram as desigualdades regionais e, principalmente, a história institucional, os tipos de cursos e a TCG anterior em cada uma das Universidades, pois enquanto a da Universidade Federal de Alfenas - UNIFAL em 2007 era 102,5\%, superior ao desejado pelo Decreto, a da Universidade Federal Rural da Amazônia - UFRA, era de 64,7\%.

Esses fatores, contudo, não foram considerados pelos formuladores da política quando traçaram a meta, evidenciando as limitações do seu diagnóstico ou do seu modelo causal e, fundamentalmente, como o contexto da prática altera as políticas formuladas. Por conseguintes, o reduzido número de instituições que alcançaram a meta indica tanto problemas na formulação do texto do Reuni quanto a recriação a que esse foi submetido pelo contexto.

\section{Referências}

ANDIFES. Associação Nacional dos Dirigentes das Instituições Federais de Ensino Superior. Relatório de acompanhamento do programa de apoio a planos de reestruturação e expansão das universidades federais (REUNI). Brasília, 2003.

ARAÚJO, M. A. D.; PINHEIRO, H. D. Reforma gerencial do Estado e rebatimentos no sistema educacional: um exame do REUNI. Ensaio, Belo Horizonte, v. 18, n. 69, p. 647- 668, out./dez. 2010.

BRASIL. Decreto $n^{\circ}$ 6.096, de 24 de abril de 2007. Institui o Programa de Apoio aos Planos de Reestruturação e Expansão das Universidades Federais - REUNI. Diário Oficial [da República Federativa do Brasil], Brasília, DF, Seção 1, p. 7, 25 de abril de 2007a.

BRASIL. Decreto Presidencial n. 6.094, de 24 de abril de 2007. Dispõe sobre a implementação do Plano de Metas Compromisso Todos pela Educação, pela União, em regime de colaboração com municípios, Distrito Federal e Estados. Diário Oficial da União, Brasília, 24 abr. 2007b.

BRASIL. Ministério da Educação. Secretaria da Educação Superior. Diretrizes gerais do programa de apoio a Planos de Reestruturação e Expansão das Universidades Federais - REUNI. Brasília - DF, 2007c. Disponível em http://portal.mec.gov.br/sesu/arquivos/pdf/diretrizesreuni. Acesso em: 5 ago. 2016.

FREY, K. Políticas públicas: um debate conceitual e reflexões referentes à prática da análise de políticas públicas no Brasil. Revista de Planejamento e Políticas Públicas, Brasília, n. 21, p. 211-259, jun. 2000. 
INEP. Sinopse Estatística da Educação Superior. Brasília, 2008. Disponível em: http://inep.gov.br/sinopses-estatisticas-da-educacao-superior. Acesso em: 20 jan. 2016.

INEP. Sinopse Estatística da Educação Superior. Brasília, 2009. Disponível em: http://inep.gov.br/sinopses-estatisticas-da-educacao-superior. Acesso em: 20 jan. 2016.

INEP. Sinopse Estatística da Educação Superior. Brasília, 2010. Disponível em: http://inep.gov.br/sinopses-estatisticas-da-educacao-superior. Acesso em: 2020 jan. 2016.

INEP. Sinopse Estatística da Educação Superior. Brasília, 2011. Disponível em: http://inep.gov.br/sinopses-estatisticas-da-educacao-superior. Acesso em: 20 jan. 2016.

INEP. Sinopse Estatística da Educação Superior. Brasília, 2012. Disponível em: http://inep.gov.br/sinopses-estatisticas-da-educacao-superior. Acesso em: 20 jan. 2016.

LIMA, L. C.; AZEVEDO, M. L. N.; CATANI, A. M. O processo de Bolonha, a avaliação da educação superior e algumas considerações sobre a Universidade Nova. Avaliação, Campinas; Sorocaba, v. 13, n. 1, 2008. Disponível em:

http://www.scielo.br/pdf/aval/v13n1/a02v13n1.pdf. Acesso em: 23 jun. 2017.

MAINARDES, J. Abordagem do ciclo de políticas: uma contribuição para a análise de políticas educacionais. Educação \& Sociedade, Campinas, v. 27, n. 94, p. 47-69, jan./abr. 2006. Disponível em: http://www.scielo.br/pdf/es/v27n94/a03v27n94.pdf. Acesso em: 4 jun. 2018.

RUA, M. G.; ROMANINI, R. Para aprender políticas públicas. Conceitos e teorias. Brasília: IGEPP, 2012. v. 1.

SABÓIA, R. M. O Reuni na UFAM: repercussões na gestão pedagógica. 2015. $185 f$ f. Dissertação (Mestrado em Educação) - Programa de Pós-Graduação em Educação da Universidade Federal da Amazônia, Manaus, 2015.

SILVA, P. L. B.; MELO, M. A. B. O processo de implementação de políticas públicas no Brasil: características e determinantes da avaliação de programas e projetos. Caderno NEPP/UNICAMP, Campinas, n. 48, p. 1-16, 2000.

ROCHA, A. V. Probabilidade e estatística. João Pessoa-PB: Editora da UFPB, 2014.

TONEGUTTI, C. A.; MARTINEZ, M. A universidade nova, o REUNI e a queda da universidade pública. v. 10, 2009. Disponível em:

www.ia.ufrrj.br/ppgea/conteudo/conteudo-2008-1. Acesso em: 4. set. 2015.

UNIVERSIDADE FEDERAL DE ALFENAS. Relatório de gestão da UNIFAL de 2012. Alfenas: UNIFAL-MG, 2013.

UNIVERSIDADE FEDERAL RURAL DA AMAZÓNIA. Relatório de gestão da UFRA de 2012. Belém: UFRA - PA, 2013. 